\title{
Solar assisted power generation system in hot desert climate: A cost-benefit perspective
}

\author{
Ramzi Alahmadi* and Kamel Almutairi** \\ * Department of Industrial Engineering, Taibah University, Madinah Munawara PO Box, Saudi Arabia \\ ** Department of Chemical Engineering, Taibah University, Madinah Munawara PO Box, Saudi Arabia \\ *Corresponding Author: rlahmadi@taibahu.edu.sa
}

Submitted : 20/08/2020

Revised :06/06/2021

Accepted : 16/06/2021

\begin{abstract}
With the increasing global concerns about greenhouse gas emissions caused by the extensive use of fossil fuels, many countries are investing in the deployment of clean energy sources. The utilization of abundant solar energy is one of the fastest growing deployed renewable sources due its technological maturity and economic competitivity. In addition to the report from the National Renewable Energy Laboratory (NREL), many studies have suggested that the maturity of solar energy systems will continue to develop, which will increase their economic viability. The focus of analysis in this paper is countries with hot desert climates since they are the best candidates for solar energy systems. The capital of Saudi Arabia, Riyadh, is used as the case study due to the country's ambitious goals in this field. The main purpose of this study is to comprehensively analyze the stochastic behavior and probabilistic distribution of solar irradiance in order to accurately estimate the expected power output of solar systems. A solar photovoltaic (PV) module is used for the analysis due to its practicality and widespread use in utility-scale projects. In addition to the use of a break-even analysis to estimate the economic viability of solar PV systems in hot desert climates, this paper estimates the indifference point at which the economic feasibility of solar PV systems is justified, compared with the fossil-based systems. The numerical results show that the break-even point of installing one KW generation capacity of a solar PV system is estimated to pay off after producing $16,827 \mathrm{KWh}$, compared to 15,422 $\mathrm{KWh}$ for the case of fossil-based systems. However, the increased cost of initial investment in solar PV systems deployment starts to be economically justified after producing $41,437 \mathrm{KWh}$.
\end{abstract}

Keywords: Solar PV system; Economic feasibility; Solar irradiance distribution.

\section{INTRODUCTION}

The substantial contribution of the electricity sector to greenhouse gas (GHG) emissions makes the generation of electricity through renewable resources a significant element of any strategy aimed at reducing GHG emissions. Therefore, major governmental initiatives and growing investments have focused on the use of renewable energy sources, such as biomass, wind, and solar energy worldwide owing to their economic and environmental advantages (Hung et al., 2014). With growing efforts aimed at alleviating the effect of the power market on climate change through minimizing carbon emissions, the energy industry must adjust to changes while undertaking generation expansion planning reviews (DeLuque \& Shittu, 2019). Consequently, the use of renewable energy sources to meet the global energy demand is continuously increasing. Renewables grew by $4 \%$ in 2018 fulfilling nearly $25 \%$ of the 
global electricity generation (IEA, 2019). Despite the supply chain disruptions in renewable industry in 2020, both in manufacturing and installments due to COVID-19 lockdown measures, the global use of renewable energy has increased. In Q1 2020, the global use of renewables in all energy sectors increased by 1.5\% compared to Q1 2019. Most of the increase in the use of renewables was driven by the growth of global share of renewables in electricity generation, which jumped from 26\% in Q1 2019 to 28\% in Q1 2020 (IEA, 2020).

The power market has contributed to a $7 \%$ growth in renewable energy output, which is greater than the $6 \%$ annual average increase since 2010 . Around $90 \%$ of the increase came from solar PV, hydropower, and wind sources (IEA, 2019). China, for instance, is strategically planning to gradually increase the proportion of renewable energy that it produces until it is the country's primary source of energy. Renewable energy in China is expected to account for $85 \%$ of the installed power capacity by 2050 , compared to $38.4 \%$ of the currently installed power capacity (CREEI, 2018). European Union (EU) countries have been increasing their renewable energy share in the energy system as well. Figure 1 shows that most of the EU member countries have added a significant share of renewable energy sources to their energy systems (Eurostat, 2018).

The switch to utilizing renewable energy sources is not limited to countries with scarce fossil fuel sources; some oil-rich countries have strategic plans to add more renewable energy sources to their countries' resources. For example, Saudi Arabia plans to increase the use of renewable energy as part of its 2030 vision. The country is targeting a $9.5 \mathrm{GW}$ generation capacity of renewable energy by 2030 as one of the country initiatives to decrease its domestic consumption of oil resources (Alquthami et al., 2020).

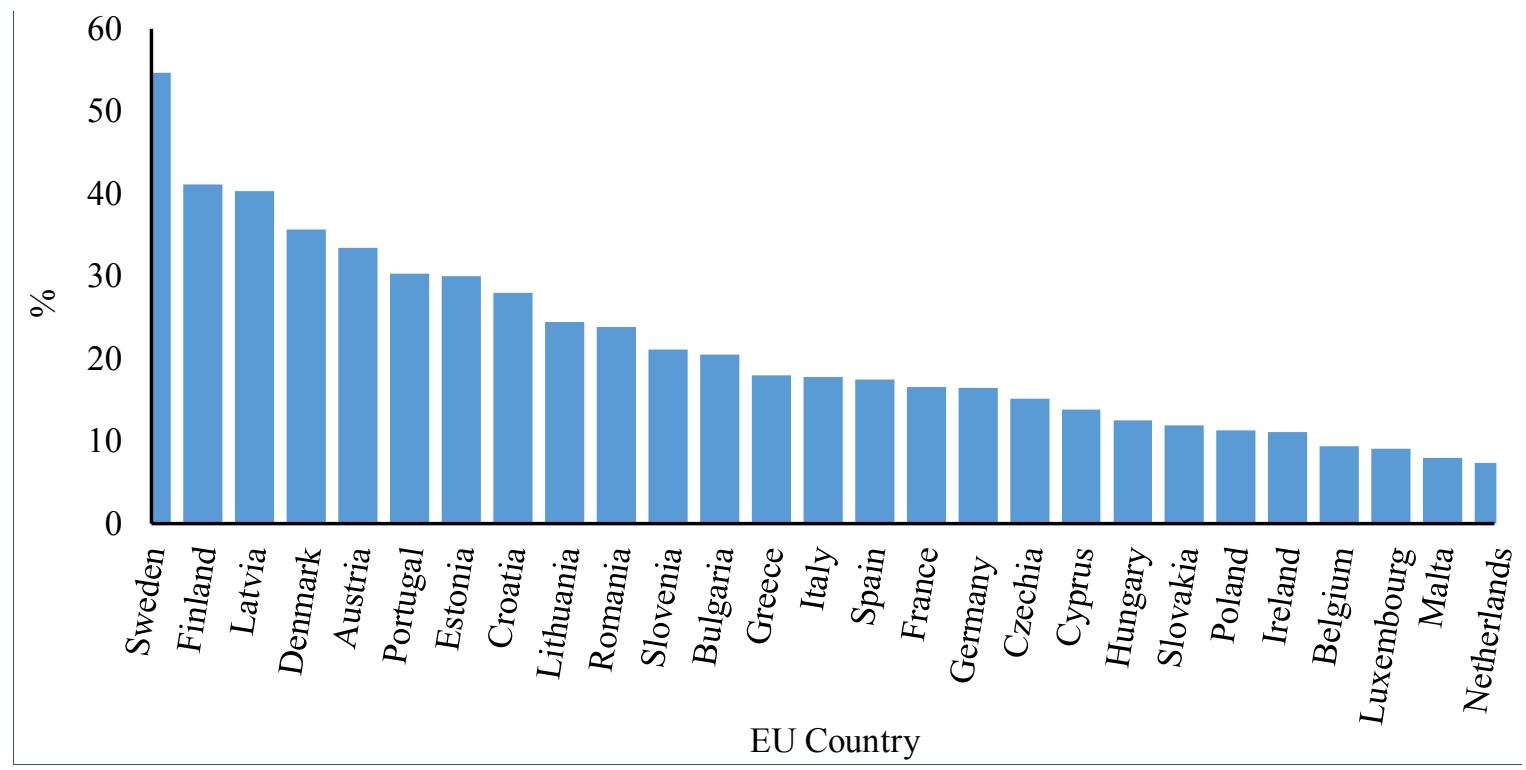

Figure 1. \% Share of Renewable Energy in Gross Energy Consumption in EU Countries (Eurostat, 2018).

The economic feasibility of renewable energy has been extensively discussed in the literature. Komendantova et al. (2018) investigated the economic feasibility of solar PV systems in the residential sector. They used the Levelized Cost of Energy (LCOE) for the economic comparisons between solar PV systems and other power generation technologies. Many other methods have been utilized in the literature, such as payback period, life cycle, 
break-even, Internal Rate of Return (IRR), and Net Present Value (NPV), to study the economic feasibility of solar PV systems (Chang \& Starcher, 2019; Owolabi et al., 2019; Sharma et al., 2019; Zeraatpisheh et al., 2018).

The contribution of this paper is to explore three principal objectives. First, the researcher will use beta distribution to model the stochastic behavior of solar irradiance in a country with a hot desert climate. Second, using a Monte Carlo simulation, the researcher will estimate the achievable capacity factor of solar systems modules in hot desert climates from the probabilistic distribution determined by the beta distribution process. Third, the researcher will use the break-even analysis to evaluate the long-term impact of the zero-variable cost of solar PV systems on the economic feasibility of solar systems' penetration in hot desert climate energy systems.

Riyadh, the capital of Saudi Arabia, is used as the case study for the analysis in this paper due to the country's ambitious goals of installing $9.5 \mathrm{GW}$ of renewable generation capacity by 2030. Riyadh's solar monitoring station, mounted by the King Abdullah City for Atomic and Renewable Energy (K.A.CARE), is located at GPS coordinates $24^{\circ} 42^{\prime 2} 27.9^{\prime \prime N} 46^{\circ} 40^{\prime} 45.1^{\prime \prime E}$ (K.A.CARE, 2021).

The remainder of this paper is structured as follows. The modeling section illustrates the beta distribution of solar irradiance. The capacity factors of the fossil-based and solar PV systems are estimated in the section that follows. After that, the economic analyses are presented. Finally, the conclusions of this paper are summarized.

\section{SOLAR IRRADINCE MODELING}

\section{Data Classification and Statistics}

This study utilized a three-year (i.e., 2013-2016) dataset of hourly solar irradiance data in the capital of Saudi Arabia, Riyadh. The data were provided by the King Abdullah City for Atomic and Renewable Energy and were prepared as part of Saudi Arabia's Renewable Resource Monitoring and Mapping (RRMM) program. This program was established to measure the potential of renewable energy resources in the country (K.A.CARE, 2021). Based on this data, each hour was considered to be one of 24 hourly segments in a day. Therefore, for the three-year period, each hour was represented by around 1,095 data points. Due to the seasonal variation of the solar irradiance levels, and to increase the accuracy of measuring the central tendency of the solar irradiance, the three-year annual data was divided into 12 seasonal data divisions. The spring, summer, fall, and winter seasons were represented by the following months, respectively: March to May, June to August, September to November, and December to February.

The statistics of solar irradiance in Saudi Arabia for the daytime period (i.e., 6 a.m.-7 p.m.) were calculated. Each segment in each season was set to be a descriptive statistic of a $\sim 365$ scored solar irradiance level. The scored solar irradiance levels are among the highest globally with a scored mean of $1000 \mathrm{~W} / \mathrm{m}^{2}$ in the summer at the peak hours; however, a significant variation exists in the scored levels between the different seasons, especially summer and winter. In addition, the statistics showed that, on average, the greatest amount of solar irradiance reached the earth between 8 a.m. and 4 p.m., and, thus, this nine-hour period will be used for the economic analysis later in the paper.

\section{Solar Irradiance Modeling and Power Output Estimation}

Solar PV power generation is characterized by randomness since it is subjected to solar irradiance variability and uncertainty. Therefore, the probabilistic behavior of solar irradiance is widely modeled by the Beta distribution Probability Density Function and has been employed by many researchers (Eladl et al., 2020; Hung et al., 2014; Sardi et al., 2017; Singh \& Fozdar, 2020; Song et al., 2020). Similar to the statistics summary of the scored solar irradiance levels referred to in the previous section, the three-year historical solar irradiance data were analyzed to obtain the 
Probability Density Function (PDF). However, and for simplicity, the daily solar irradiance distribution for each season was assumed to be represented by one hour (i.e., 3 p.m.), which appears to receive an hourly average solar irradiance level. In the summer, for instance, the three-year average of daytime seasonal solar irradiance level ranges between $\sim 100 \mathrm{~W} / \mathrm{m}^{\wedge} 2$ and $\sim 900 \mathrm{~W} / \mathrm{m}^{\wedge} 2$, and the average solar irradiance level scored at 3 p.m. comes the closest to represent the daytime average.

The approach to obtain the PDF for solar irradiance has been outlined in many publications (Eladl et al., 2020; Hung et al., 2014; Song et al., 2020). The PDF for solar irradiance is produced as follows:

$$
f(x)= \begin{cases}\frac{\Gamma(\alpha+\beta)}{\Gamma(\alpha) \Gamma(\beta)} x^{(\alpha-1)}(1-x)^{(\beta-1)}, & 0 \leq x \leq 1, \alpha, \beta \geq 0 \\ 0, & \text { otherwise }\end{cases}
$$

where $f(x)$ is the distribution function of $\mathrm{x}$, and $\mathrm{x}$ is the random variable of solar irradiance $\left(\mathrm{kw} / \mathrm{m}^{2}\right)$, where each hour is assumed to have 20 states of solar irradiance with a step of $0.05 \mathrm{kw} / \mathrm{m}^{2}$. The $\alpha$ and $\beta$ values for each season are the shape paramaters of $f(x)$, which are calculated using the mean $(\mu)$ and standard deviation $(\sigma)$ as follows:

$$
\beta=(1-\mu)\left(\frac{\mu(1+\mu)}{\sigma^{2}}-1\right) \quad \alpha=\frac{\mu \times \beta}{1-\mu}
$$

The values of beta distribution $\alpha$ and $\beta$ for the four seasons are summarized in Table 1 .

Table 1. Beta distribution shape parameter values for spring, summer, fall, and winter.

\begin{tabular}{|c|c|c|c|c|}
\hline & Spring & Summer & Fall & Winter \\
\hline$\alpha$ & 6.62 & 20.30 & 8.53 & 8.40 \\
\hline$\beta$ & 3.60 & 6.62 & 7.51 & 8.35 \\
\hline
\end{tabular}

Then, the PDF was generated after determining the probability of the solar irradiance state as follows:

$$
\rho(x)=\int_{x_{1}}^{x_{2}} f(x) d x
$$

where $\rho(x)$ is the probability of the solar irradiance state at a given time during the day, and $x_{1}$ and $x_{2}$ are beginning and end limits of the solar irradiance state $\mathrm{x}$, respectively.

Figure 2 shows the PDF produced from the historical solar irradiance data based on the beta distribution shape parameters, minimum and maximum values for the 20 solar irradiance states at 3 p.m. for the spring, summer, fall, and winter seasons. Even though the solar states in the different seasons are promising, clearly, the density of the solar irradiance state is season-dependent. During the summer season, the greatest amount of solar irradiance density falls onto the surface with a narrower distribution about the mean, followed by spring season, while the amount of 
solar irradiance in the fall and winter seasons is about the same, following the solar density in the summer and spring seasons.

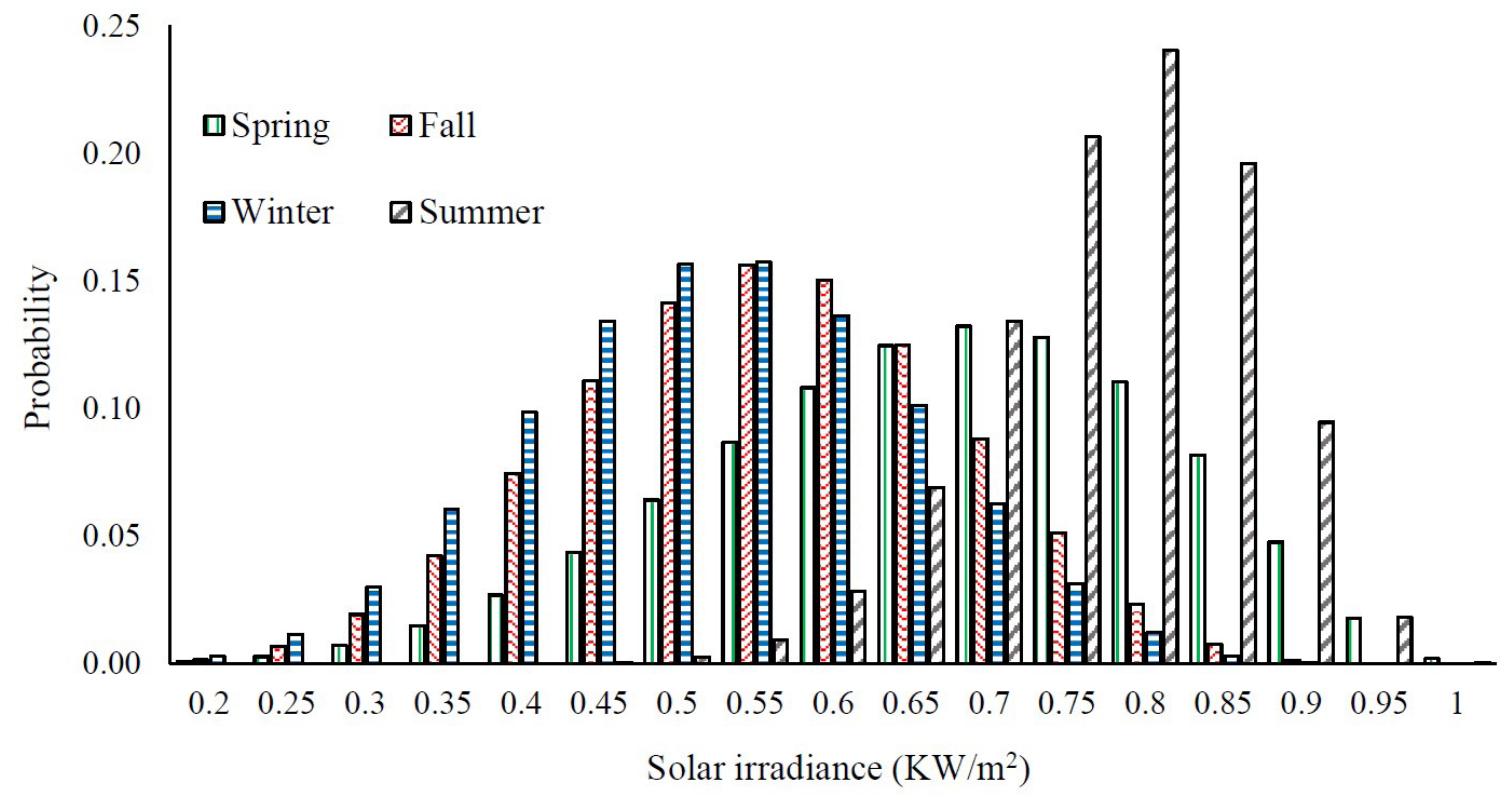

Figure 2. Probability density for solar irradiance.

To estimate the output of the solar PV module $\left(P V_{o}\right)$ at solar irradiance state $\mathrm{x}$, Equation 4 as demonstrated and employed in many papers such as (Atwa et al., 2010; Hung et al., 2014; Khatod et al., 2013; Teng et al., 2013) is used for the calculation:

$$
P V_{o}(x)=N \times F F \times V_{y} \times I_{y}
$$

where

$$
\begin{aligned}
& F F=\frac{V_{M P P} \times I_{M P P}}{V_{o c} \times I_{x c}} \\
& V_{y}=V_{o c}-K_{v} \times T_{c y} \\
& I_{y}=x\left[I_{x c}+K_{i} \times\left(T_{c y}-25\right)\right] \\
& T_{c y}=T_{A}+x\left(\frac{N_{O T}-20}{0.8}\right)
\end{aligned}
$$

where the parameters are defined in Table 2. 
Table 2. PV module characteristics (Khan \& Malik, 2017).

\begin{tabular}{|c|c|c|c|}
\hline \multicolumn{2}{|c|}{ PV Module Characteristics } & \multirow{2}{*}{ Value } \\
\cline { 1 - 3 } Symbol & Unit & Definition & 7.76 \\
\hline$I_{M P P}$ & Ampere $(A)$ & Current at maximum power point & 28.36 \\
\hline$V_{M P P}$ & Volt $(\mathrm{V})$ & Voltage at maximum power point & 43 \\
\hline$N_{O T}$ & ${ }^{\circ} \mathrm{C}$ & Nominal cell operating temperature & 8.38 \\
\hline$I_{x c}$ & $\mathrm{~A}$ & Short circuit current & 36.96 \\
\hline$V_{o c}$ & $\mathrm{~V}$ & Open circuit voltage & 0.00545 \\
\hline$K_{i}$ & $\frac{A}{{ }^{\circ} \mathrm{C}}$ & Current temperature coefficients & 0.1278 \\
\hline$K_{v}$ & $\frac{V}{{ }^{\circ} \mathrm{C}}$ & Voltage temperature coefficients & Data \\
\hline$T_{A}$ & ${ }^{\circ} \mathrm{C}$ & Ambient temperature & Calculated \\
\hline$T_{c y}$ & ${ }^{\circ} \mathrm{C}$ & Cell temperature & \\
\hline
\end{tabular}

Figure 3 presents the expected power output $P V_{o}($ Watt $)$ of a solar PV module at solar irradiance state $\mathrm{x}$ for 3 p.m. for the four seasons. The hourly predicted power outputs at 3 p.m. in the spring, summer, fall, and winter, which are represented by the area under the curves in Figure 3, are $124.5(\mathrm{Wh}), 138.69(\mathrm{Wh}), 104.39(\mathrm{Wh})$, and 103.07 (Wh), respectively. Similar to the patterns in Figure 1, the power output in the summer is expected to be the highest, while the power outputs in the fall and winter are expected to be the lowest.

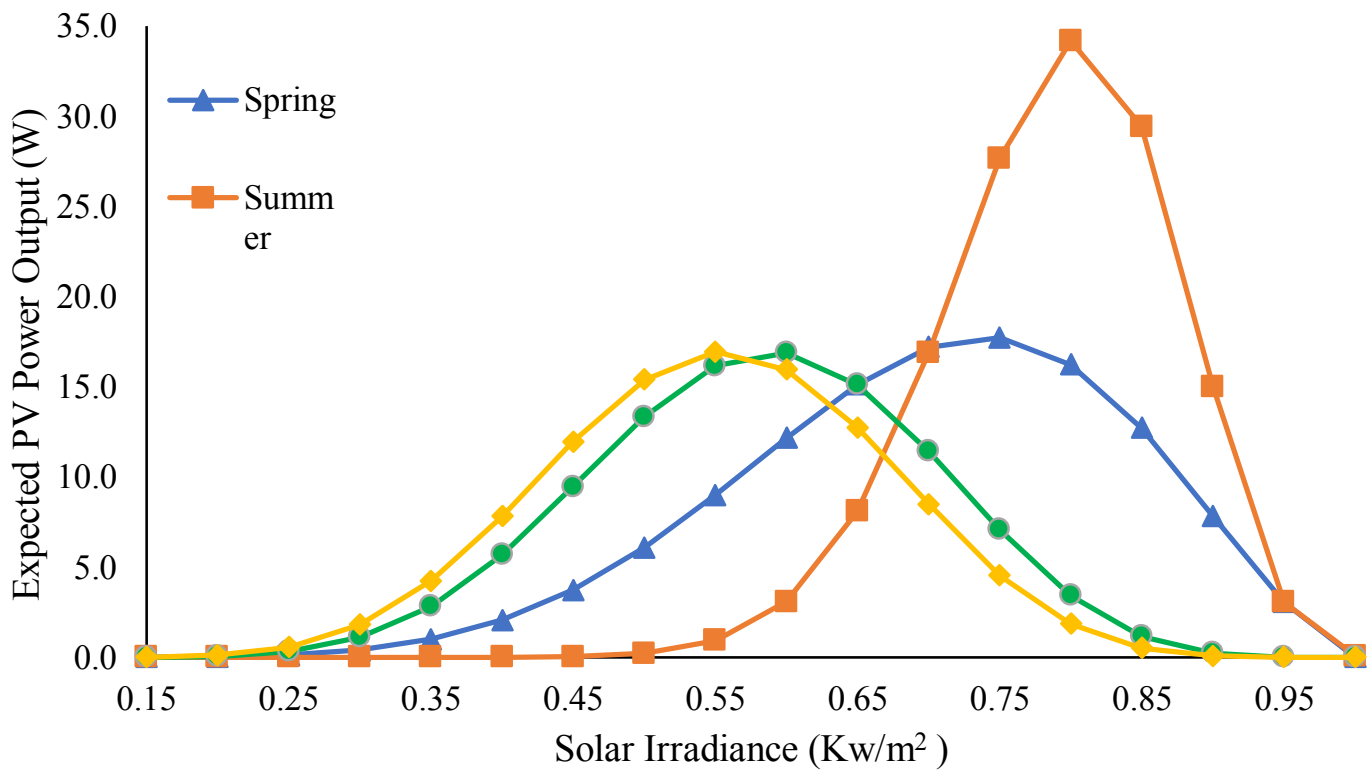

Figure 3. Estimated power output of a solar PV module at hour 3 p.m. 


\section{CAPACITY FACTOR ESTIMATION}

\section{Fossil-Based Power System Capacity Factor Estimation}

The power industry in Saudi Arabia is primarily regulated by the Saudi Electricity Company. The company has the capacity to produces $65 \%$ of the generation capacity and purchases most of the output capacity of its partners to supply the electricity demand in the nation (ECRA, 2021). After classifying the electricity demand data from 2020 as published by Water \& Electricity Regulatory Authority (ECRA), the seasonal demand minimum, mean, and maximum were calculated (see Table 3). A seasonality behavior exists to the demand, where about a $40 \%$ variation exists between electricity demand in the summer and winter seasons. The increase of electricity demand in the summer is caused by the increased use of air conditioning (AC) due to elevated air temperatures, which increase the heat island effect and the need for AC consequently. The heat island effect in urban areas is created by the released heat of $\mathrm{AC}$ units (indoor) to the surrounding outdoor areas (Takane et al., 2017).

Table 3. Seasonal power demand mean, maximum and minimum in 2020 (ECRA, 2021).

\begin{tabular}{|c|c|c|c|c|}
\hline & Spring & Summer & Fall & Winter \\
\hline Mean (MWh) & 44,765 & 61,464 & 50,572 & 37,489 \\
\hline Max (MWh) & 54,360 & 64,390 & 61,984 & 39,048 \\
\hline Min (MWh) & 37,972 & 58,045 & 38,918 & 36,013 \\
\hline
\end{tabular}

Then, the capacity factor (CF) for the current fossil-based power system was calculated utilizing Equation 5 as follows (Zhao et al., 2019):

$$
C F=\frac{\sum \text { Net Plants Generation }}{\sum \text { Plants Capacity } \times \text { Hours }}
$$

The seasonal capacity factors vary significantly. The capacity factors for spring, summer, fall, and winter were found to be $52.6 \%, 72.2 \%, 59.4 \%$, and $44 \%$, respectively. In the summer season, the power generation capacity was mostly utilized to supply the increased demand for air conditioning due to rising air temperatures. On the other hand, the power generation capacity is the least utilized in the winter due to the drop in power demand as winters in the hot desert climates are moderate. Therefore, there is no need to install heating units, and most of the power consumption comes from the industrial and commercial sectors, compared to low residential power demand.

\section{Solar PV System Capacity Factor Estimation}

Similar to the capacity factor estimation for the fossil-based power system, the expected capacity factor for the solar PV system was calculated using Equation 5. However, unlike the fossil-based power system, the number of daily generation hours was assumed to be nine hours (i.e., 8 a.m. -4 p.m.) since these hours present the highest solar irradiance levels. In addition, due the stochastic behavior of solar irradiance availability (see Figure 3), which affects the power output of the solar PV system, a Monte Carlo simulation was used to generate a 1000-sample set of solar irradiance realizations.

The aim of the simulation model is to estimate the achievable capacity factor of solar system modules over the different weather seasons, considering both the reliability and availability of solar irradiance. The expected mean $\mu$, standard deviation $\sigma$, minimum, maximum, and estimated capacity factor (CF) of the solar PV power output are 
summarized in Table 4. The results show that the achievable capacity factor rates in spring, fall, and winter are lower than those in summer, which is explained by the density of the solar irradiance in summer as shown in Figure 2 . The mean and standard deviation were calculated using the basic probability expected value and standard deviation formulas as follows:

$$
\begin{aligned}
& \mu=E\left[P V_{o}\right]=\sum_{x=1}^{k} P V_{o}(x) \cdot p(x) \\
& \sigma=\sqrt{\operatorname{Var}\left(P V_{o}\right)}=\sqrt{E\left[\left(P V_{o}-E\left(P V_{o}\right)\right)^{2}\right]}
\end{aligned}
$$

Table 4. Mean, standard deviation, maximum, minimum, and capacity factor of the simulated output power of solar PV capacity during different weather seasons.

\begin{tabular}{|c|c|c|c|c|}
\hline & Spring & Summer & Fall & Winter \\
\hline$\mu \quad\left(W / m^{2}\right)$ & 123.56 & 138.84 & 103.96 & 102.00 \\
\hline$\sigma \quad\left(W / m^{2}\right)$ & 25.13 & 13.89 & 21.01 & 21.64 \\
\hline $\operatorname{Max}\left(W / m^{2}\right)$ & 203.52 & 179.12 & 169.62 & 163.55 \\
\hline $\operatorname{Min}\left(W / m^{2}\right)$ & 33.80 & 93.50 & 27.41 & 31.66 \\
\hline$C F \%$ & 24 & 28.13 & 22.5 & 22.5 \\
\hline
\end{tabular}

\section{ECONOMIC ANALYSIS}

After the realization of expected achievable capacity factors of fossil- and solar PV-based power generation systems, the levelized cost of energy (LCOE) for both systems was found. The LCOE of the installed fossil-based power systems was adopted from EIA (2020) due to the complexity of estimating the variable O\&M cost because of the high uncertainty associated with fossil fuel prices. A weighting method, based on the different installed power generation technologies, was employed to calculate a representative LCOE of the fossil-based power systems.

On the other hand, the LCOE of the solar PV-based power system was calculated as follows (NREL, 2019):

$$
L C O E=\frac{C C * C R F+F C}{8760 * C F}
$$

Where

$$
C R F=\frac{i *(i+1)^{n}}{(1+i)^{n}-1}
$$

where $\mathrm{CC}$ is the overnight capital cost $(\$ / \mathrm{kW}), \mathrm{CRF}$ is the capital recovery factor, $\mathrm{FC}$ is the fixed O\&M cost ( $\$ / \mathrm{kW}$-year), CF is the capacity factor, $\mathrm{i}=10 \%$ is the interest rate, and $\mathrm{n}=30$ is the number of received annuities.

Then, the break-even analysis was used to find the point at which no profit is gained, but the sales value covers the expenses. This analysis was employed in two stages. First, it was done for the fossil-based power production assortment. The break-even point (BE1) was 15,422 KWh (see Figure 4). Similarly, the break-even point analysis 
was employed to evaluate the effect of increasing the (fixed) investment in solar PV systems, compared to fossilbased systems, to reduce the variable cost of power production and attain environmental benefits.

The objective of this comparison was to assess the long-term impact of the zero-variable cost of the solar PV systems on their economic feasibility related to hot desert climate energy systems. Figure 5 shows that the breakeven point shifted from BE1 $(15,422 \mathrm{KWh})$ to BE2 $(16,827 \mathrm{KWh})$. However, BE2 is not the point where the investment in solar PV systems is justified if the environmental benefits are excluded. The profit difference between BE1 and BE2, which can be made through fossil-based power plants without the added cost investment in solar PV systems, is estimated at $\$ 106.50$, which does not pay off for the difference in the cost of investment between the two technologies. Therefore, the investment in a solar PV system can only be justified at point $1(41,437 \mathrm{KWh}$ ) (see Figure 5), where the total cost (TC1) of fossil-based power production and the total cost (TC2) of solar PV based power production are equal. It is at this point where the cost of the fixed investment in solar PV systems or fossil-based systems is indifferent. The basic evaluation of break-even point was carried out as follows (Kucharski \& Wywial, 2019; Fuksa et al., 2017):

$$
\begin{aligned}
& S(\text { selling value })=x . c=T C(\text { total cost })=c_{f}+x \cdot c_{v} \\
& B E=\frac{c_{f}}{c-c_{v}}
\end{aligned}
$$

Since this study is analyzing the break-even analysis of multiple power generation assortments, the power production was fixed, and variable costs margined based on the different contributions of the generation technologies in the power system. Therefore, $c_{f}$ is factored into the contribution margin of each power generation technique as follows:

$$
c_{f_{i}}=c_{f f} \cdot X_{f_{i}}
$$

where

$$
\begin{aligned}
c_{f f} & =\frac{c_{f}}{X_{f}} \\
X_{f} & =\sum_{i=1}^{r} X_{f_{i}}=\sum_{i=1}^{r} x_{f_{i}} \cdot x=\sum_{i=1}^{r}\left(c-c_{v_{i}}\right) \cdot x \\
B E_{i} & =\frac{c_{f_{i}}}{\left(c-c_{v_{i}}\right)}
\end{aligned}
$$

where

$c$ : power selling price

$x$ : the amount of sold power

$c_{f_{i}}$ : total fixed cost of power generation through power generation technology $\mathrm{i}$

$c_{v_{i}}$ : variable cost of power generation through power generation technology $\mathrm{i}$

$c_{f f}$ : total fixed cost of power generation mark-up factor of different technologies

$X_{f}$ : achieved global marginal contribution of different power generation technologies through sales. 


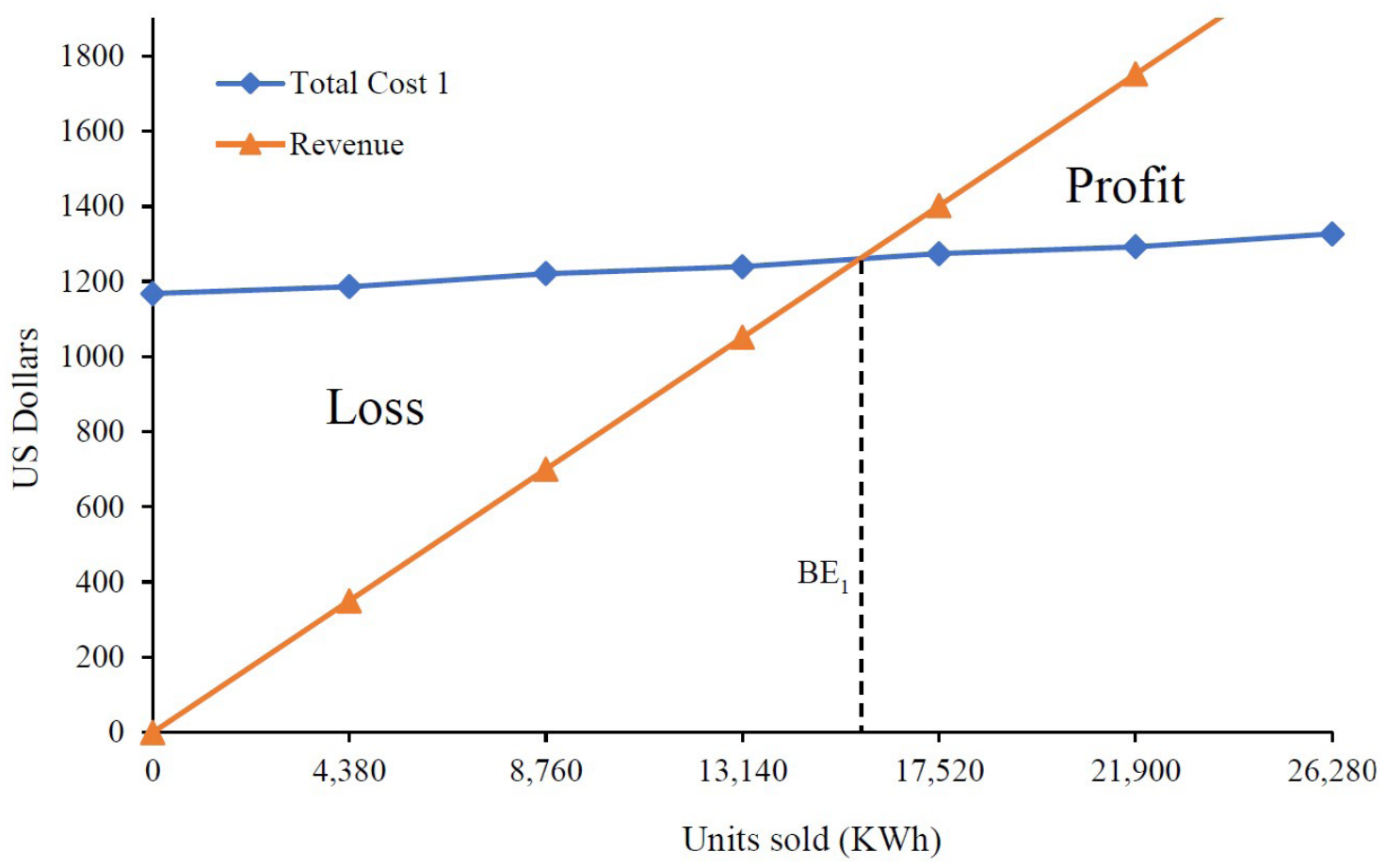

Figure 4. One kilowatt installed fossil fuel-based power capacity break-even chart.

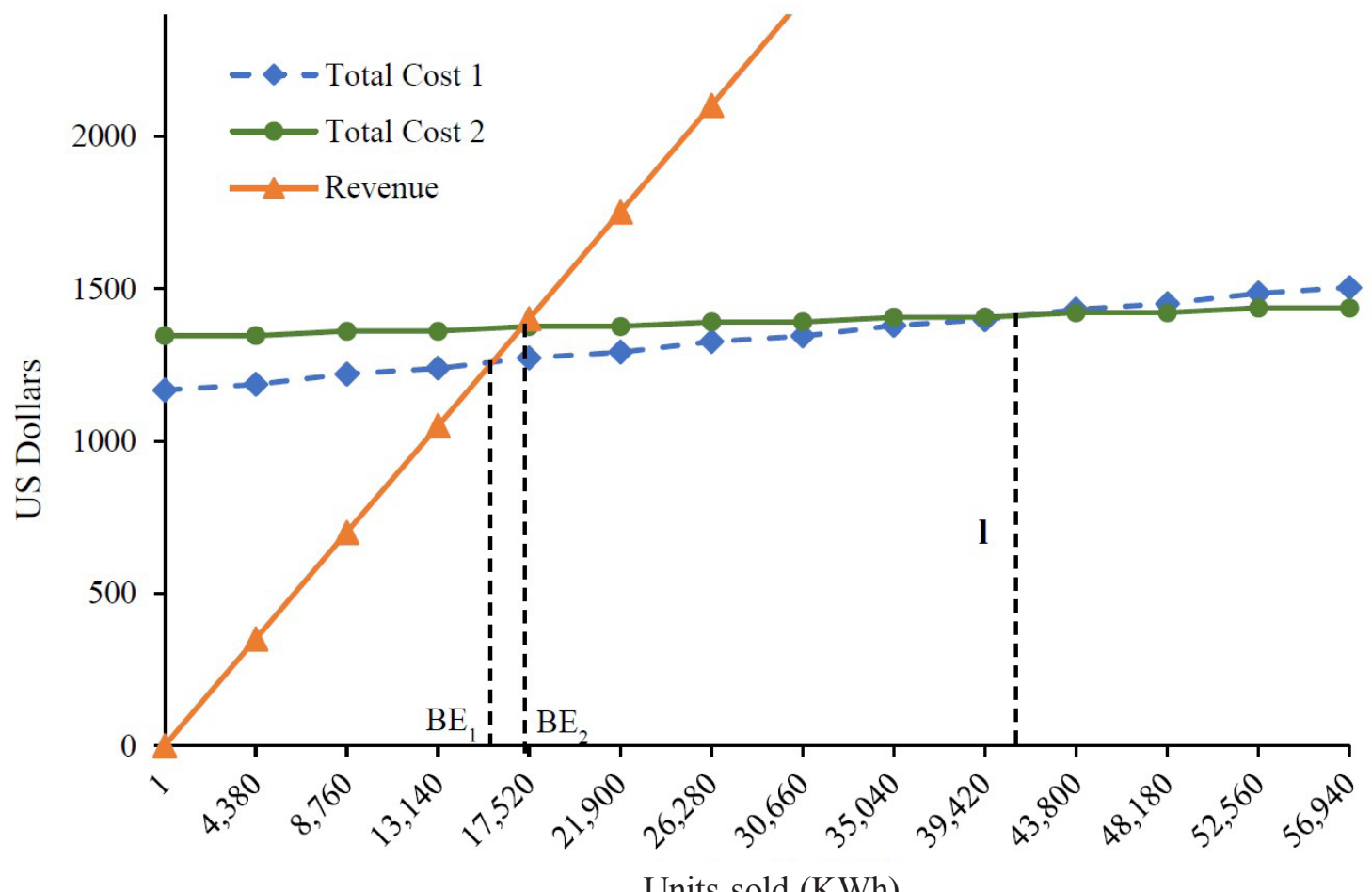

Units sold (KWh)

Figure 5. One kilowatt installed power capacity break-even chart showing the effect of solar energy integration into the power system. 


\section{CONCLUSIONS}

In this paper, a break-even analysis was proposed as a cost-benefit approach to evaluate the economic feasibility of investment in solar PV power generation systems. This analysis supports strategic planning units and decisionmaking teams in the power generation sector and foresees the long-term impact of Solar PV system's zero-variable cost on the system's feasibility, compared to fossil-based systems. A literature review and an in-depth analysis were presented to predict the stochastic behavior of solar irradiance to increase the accuracy of the economic conclusions about the deployment of solar PV systems for power generation.

The findings of this paper suggest that the deployment of solar PV systems in hot desert climates is economically feasible due to the intensity of the solar irradiance. The expected short-term, break-even points for fossil-based power and solar PV generation systems are relatively close. However, it is estimated that investment in solar PV systems for power generation, compared to fossil-based systems, will be more economically preferable in the long term. In addition, as the technological maturity of solar PV systems continues to develop, the economic feasibility of the deployment of solar systems will be more encouraging.

Many other initiatives consider the deployment of renewable sources for energy generation to reduce the green gas emissions produced by fossil-based power generation systems and to maintain a sustainable supply to meet the domestic demand of energy. Therefore, further studies are suggested to explore other renewable energy sources to find the optimized power generation technology assortment that achieves the best technical and economic objectives.

\section{ACKNOWLEDGMENT}

The authors would like to thank King Abdullah City for Atomic and Renewable Energy (K.A.CARE) for providing the access to the hourly solar irradiance data for Saudi Arabia, which was prepared under Saudi Arabia's Renewable Resource Monitoring and Mapping (RRMM) program.

\section{REFERENCES}

Alquthami, T., Sreerama Kumar, R., \& Shaikh, A. Al. 2020. Mitigation of voltage rise due to high solar PV penetration in Saudi distribution network. Electrical Engineering 102: 881-890.

Atwa, Y.M., El-Saadany, E.F., Salama, M.M.A., \& Seethapathy, R. 2010. Optimal renewable resources mix for distribution system energy loss minimization. IEEE Transactions on Power Systems 25: 360-370.

Chang, B. \& Starcher, K. 2019. Evaluation of wind and solar energy investments in Texas. Renewable Energy 132: 1348-1359.

DeLuque, I. \& Shittu, E. 2019. Generation capacity expansion under demand, capacity factor and environmental policy uncertainties. Computer \& Industrial Engineering 127: 601-613.

Water \& Electricity Regulatory Authority (ECRA). 2021. https://www.ecra.gov.sa/en-us/Pages/default.aspx.

Eladl, A.A., El-afifi, M.I., Saeed, M.A., \& El-saadawi, M.M. 2020. Optimal operation of energy hubs integrated with renewable energy sources and storage devices considering $\mathrm{CO} 2$ emissions. Electrical Power and Energy Systems Vol. 117.

European Statistical System (Eurostat). 2018. https://ec.europa.eu/eurostat.

Hung, D.Q., Mithulananthan, N., \& Lee, K.Y. 2014. Determining PV penetration for distribution systems with time-varying load models. IEEE Transactions on Power Systems 29: 3048-3057. 
International Energy Agency (IEA). 2019. Global Energy Review https://www.iea.org/.

International Energy Agency (IEA). 2020. Global Energy Review https://www.iea.org/.

King Abdullah City for Atomic and Renewable Energy (K.A.CARE). 2021. Renewable Resource Monitoring and Mapping Program.

Khatod, D.K., Pant, V., \& Sharma, J. 2013. of Renewable Distributed Generators. IEEE Transactions on Power Systems 28: 683-695.

Komendantova, N., Schwarz, M.M., \& Amann, W. 2018. Economic and regulatory feasibility of solar PV in the Austrian multi-apartment housing sector. AIMS Energy 6: 810-831.

Kucharski, R. \& Wywial, J.L. 2019. Optimization of the break-even point for non-homogeneous products sales. Theoretical Journal of Accounting 101: 133-149.

Owolabi, A.B., Nsafon, B.E.K., \& Huh, J.S. 2019. Validating the techno-economic and environmental sustainability of solar PV technology in Nigeria using RETScreen Experts to assess its viability. Sustainable Energy Technologies and Assessments 36: 100542.

Rentowno, P., Produkcji, Ś.C.I., Przyk, N.A., Przedsi, L.A., \& Górniczych, E.B. 2017. Breakeven Analysis Based On Mining Companies 62: 33-44.

Sharma, S. K., Palwalia, D. K., \& Shrivastava, V. 2019. Performance analysis of grid-connected $10.6 \mathrm{~kW}$ (commercial) solar PV power generation system. Applied Solar Energy, 55(5), 269-281.

Sardi, J., Mithulananthan, N., Gallagher, M., \& Hung, D.Q. 2017. Multiple community energy storage planning in distribution networks using a cost-benefit analysis. Applied Energy 190: 453-463.

Singh, S. \& Fozdar, M. 2020. Double-sided bidding strategy for power suppliers and large buyers with amalgamation of wind and solar based generation in a modern energy market. IET Generation, Transmission \& Distribution, 14(6), 1031-1041.

Song, X., Tan, Z., Zhao, R., \& De, G. 2020. A fuzzy-based multi-objective robust optimization model for a regional hybrid energy system considering uncertainty. Energy Science \& Engineering 8(4): 926-943.

Takane, Y., Kikegawa, Y., Hara, M., Ihara, T., \& Ohashi, Y. 2017. A climatological validation of urban air temperature and electricity demand simulated by a regional climate model coupled with an urban canopy model and a building energy model in an Asian megacity. International Journal of Climatology 37: 10351052.

Teng, J.H., Luan, S.W., Lee, D.J., \& Huang, Y.Q. 2013. Optimal charging/discharging scheduling of battery storage systems for distribution systems interconnected with sizeable PV generation systems. EEE Transactions on Power Systems 28: 1425-1433.

U.S. Energy Information Administration's (EIA). 2020. Levelized Cost and Levelized Avoided Cost of New Generation Resources in the Annual Energy Outlook.

Zeraatpisheh, M., Arababadi, R., \& Pour, M.S. 2018. Economic analysis for residential solar PV systems based on different demand charge tariffs. Energies 11(12): 3271.

Zhao, Z., Member, Student, Wang, C., Member, Senior, Liao, H., \& Miller, C.J. 2019. Data-driven Analysis of Regional Capacity Factors in a Large-Scale Power Market: A Perspective from Market Participants. Proceedings of the 2019 North American Power Symposium (NAPS), pp. 1-6. IEEE. 